\title{
Sport, Make-believe, and Volatile Attitudes ${ }^{1}$ Nils-Hennes Stear
}

In 1941, as German bombs fell around Britain during the Blitr, a list of "temporary rules" attributed to Richmond Golf Club began circulating in newspapers. The rules explain how to proceed with a game of golf given certain hazards of war. Rule 2, for instance, stipulates that "during gunfire or while bombs are falling, players may take shelter without penalty for ceasing play." 'Though the document's veracity is unclear, the rules supply a caricature of the apparent absurdity all competitive games share: sometimes, we appear to care intensely about their outcomes, even as bombs fall about our feet, while acknowledging that those outcomes do not matter. I call this the Purzle of Sport.

In this paper I argue that the only published solution to this puzzle, according to which our puzzling attitudes to competitive game outcomes are explained by make-believe, ${ }^{2}$ suffers a number of problems. I then offer a new solution using ideas from David Velleman and Thomas Nagel, which appeals to attitudinal volatility. Finally, I consider how make-believe might still figure in my account.

Why do we often (appear to) care so much about competitive game outcomes (understood broadly to include outcomes of whole games, of individual plays, whether a record is broken, etc.) while simultaneously denying their importance? Kendall Walton's answer is that make-believe explains this: just as we engage in rule-governed imaginative activity when playing children's games or appreciating works of fiction, so we sometimes engage in this activity when participating as player or spectator $^{3}$ in competitive games (Walton 2015a, 75-76). Specifically, while participants may not actually believe some competitive game outcome matters, they

1 Thanks to Ken Walton, Bryan Parkhurst, Derek Matravers, Dan Jacobson, Gregg Crane, Sarah Buss, participants in both Michigan's Candidacy Seminar (2013-14) and the Graduate Student Working Group, audiences at the University of Lund and the annual meeting of the American Society for Aesthetics (2013), two anonymous referees, the editors, and to Andy and Marita Standen, in whose home this paper was first drafted. This article was made possible by support from UNAM's Postdoctoral Fellowships Programme.

2 This solution is worked out in most detail by Kendall Walton in (Walton 2015a), which will be the main focus of my discussion, though Paul Taylor also offers a version of it in (Taylor manuscript). Bernard Suits might also be taken to subscribe to it, insofar as he gives a single analysis to cover both competitive and make-believe games. Suits is interested in analysing the broader notion of a game, of which he takes make-believe and competitive games to be kinds. While Walton begins with traditional make-believe (as well as artistic representation) and eventually extends his theory to competitive games, Suits reverses this, beginning with competitive games and extending it to traditional make-believe games. See (Suits 1978).

3 I use 'participate' and grammatical variants throughout to refer to competing and spectating. 
engage imaginatively in a make-believe game in which it is fictional-true in the game- that it matters a lot. Call this claim 'Sports ${ }^{4}$ as Make-believe' (SMB).

What is a competitive game? I will leave this question without a precise answer. At minimum, a set of necessary conditions upon $x^{\prime}$ s being a competitive game are that $x$ be (i) an activity (ii) participated in (iii) with success conditions in mind, what Bernard Suits calls 'prelusory' goals (Suits 1978, 36-37). Paradigmatic examples have to suffice to anchor the notion: football, tennis, and basketball, as well as 'It', 'British Bulldog', and similar children's games count. Making toast, waiting for the bus, filing one's taxes do not. ${ }^{5}$

\section{II}

A putative analogy between how we engage with fiction and sport motivates SMB. Both activities can seem similarly puzzling. First, we easily recover from sporting as from fictional tragedies, even deeply moving ones. Walton writes:

Many forget the game quickly after it is over, much too quickly for people who care as much as they seem to care during the game [...] It is hard to resist comparing the avid sports fan to the playgoer who sheds bitter and voluminous tears over the tragic fate of Romeo and Juliet, and twenty minutes later has a jolly good time with her friends at an espresso bar. [...] Afterwards, like the playgoer, she steps outside of the make-believe and goes back to living her life as though nothing much had happened-even if the home team suffered a devastating and humiliating defeat. It's just a story; it's just a game. (Walton 2015a, 77)

A person undergoes a play's emotional pitch and roll. The curtain falls, her tears dry, and life continues unperturbed. A sports fan rejoices as her team scores and agonizes when it repeatedly concedes. The game ends, she sighs, and life goes on unperturbed. On SMB, both spectators engage in makebelieve during the spectacle, and return to actuality afterwards. Because of how make-believe attitudes operate in our psychological economy, they promise to explain our ability to appear to care greatly about something one minute and forget about it the next.

Second, our behaviour while participating in competitive games, as when engaging with fictions, suggests we care greatly about their outcomes, despite how little seems at stake - a fact we sometimes concede at a calmer hour. Walton again:

4 I use 'sport' and 'competitive game' interchangeably throughout. The concepts are distinct, however. See (Schneider 2001), (Suits 1988).

5 Making toast and filing taxes could be competitive games, embedded in the right context. A lot hangs on what falls under the concept GAME. Giving a successful account of this concept is notoriously tricky, as Wittgenstein notes, but mercifully beyond the scope of this paper. Whatever the correct account is, provided it is not horrendously revisionary, can be plugged into the discussion. 
Why should people care about the Yankees or the Red Sox? Their fortunes on the field have no obvious bearing on the welfare of most fans. Why does it matter whether the home team wins or loses? Life will go on just as it did before, regardless. But the spectators, some of them, scream their hearts out during the game, as though it is a matter of life and death. Some people pick which players to "like", which ones to root for, more or less arbitrarily, on whims [...]. Yet they may let themselves be carried away during the game, as though genuine and substantial values or self-interest is at stake. (Walton 2015a, 76-77)

To facilitate expression, I will say that the extent to which a competitive game outcome moves us to excitement evinces our caring-attitudes toward that outcome. The extent to which we explicitly (dis)avow a competitive game outcome's importance "in the cold light of day" evinces prima facie the amount we believe the outcome to matter. Now one can express the puzzle like so: why are participants' caring-attitudes towards competitive game outcomes so intense, when they do not believe those outcomes matter? Of course, it is worth noting an important qualification here. Some competitive game outcomes can and do matter to us - really matter. Competitive game outcomes can matter to us instrumentally, for instance, because consequences of real importance depend on them (Walton 2015a). The Iraq national football team under Uday Hussein, for instance, had good reason to care; Hussein would motivate them "by threatening to amputate their legs if they lost" (Kuper \& Szymanski 1990, p. 278) among other outrages. So, the question applies only to some instances of participation.

Considering another more famous puzzle, the Paradox of Fiction, will help clarify the present one, as well as SMB:

(1) Things that we believe do not exist cannot be the intentional objects of our emotions (under the same description). ${ }^{6,7}$

(2) We believe that fictional events or characters per se do not exist.

(3) Fictional events and characters per se are the intentional objects of our emotions. ${ }^{8}$

6 The qualification avoids Frege-puzzle type cases involving unknown identities that would otherwise falsify (1). Amilie might love Orwell and thus Blair-because Orwell is Blair-despite believing Blair does not exist.

7 Of course, possible events can be the objects of intentional attitudes. But fictions are distinctive in that our disposition to respond to them does not track probability as our responses to possible events do. Ordinary appreciators get worked up about fictional events even when knowing they could never be actual. But rational people contemplating possibilities are more or less worked up as a possibility becomes more or less likely, respectively. Cases in which someone gets worked up about far-flung possibilities are too close to the explanandum to supply a counterexample (Radford 1975, 73-74).

8 The puzzle is sometimes posed (sometimes implicitly) in the following way: (1) We respond emotionally to a thing only if we believe it is real; (2) We do not believe the events or characters in fictions are real; (3) We respond emotionally to the events and characters in fictions; see (Radford 1975), (Stear 2009, 26). However, this is ambiguous. "Respond emotionally to" can be read causally_fictional entities cause our emotions- 
To resolve the paradox, one must reject one of the three propositions, assuming there is no ambiguity. But this is tricky. Claim (1) looks undeniable; it seems impossible to emote about something one believes does not exist (notwithstanding the puzzling case of fiction itself). Claim (2) is likewise difficult to deny. Despite talk of "suspending disbelief", we clearly do not doubt Sherlock Homes' non-existence, for instance. But claim (3) also looks right. After all, we speak naturally of loathing James Bond, feeling sorry for John Flory, and admiring Jane Eyre. Pretheoretically, this talk appears quite literal.

There are doubts about whether Walton's theory of make-believe really addresses the Paradox of Fiction as framed in the literature, and how important solving this puzzle is to the theory (by my lights, not very). ${ }^{9}$ Nevertheless, the way I frame the Paradox, and how the theory solves it, can help clarify the theory's relevance to the Puzzle of Sport. Walton's solution is to deny (3). ${ }^{10}$ The proposal is that it is not literally true-true at the actual world-that, for instance, I loathe James Bond, since I know there is no James Bond. Rather, it is fictional that I loathe him. Correspondingly, my utterance 'James Bond is loathsome' asserts no proposition (not the obvious one anyway), but instead makes it fictional that I assert that James Bond is loathsome; the speech-act conceals a fictionality operator with scope over the whole sentence. Similarly, when I gag as Bond oozes misogyny, it is not literally true that he disgusts me (even if I literally feel disgust); it is fictional that he does. What is literally true is that the film causes certain physiological sensations in me, such as the need to gag, whether or not these constitute genuine emotions. Walton's profound insight is that these physiological sensations, which he calls "quasi-emotions", serve as "props" in make-believe games "playing the part" of real emotions. Returning to James Bond, the actual gagging sensation combines with what Walton calls a "principle of generation"-a function from true propositions to fictional ones-making it fictional in the game I play with the film that James Bond disgusts me. This happens in much the same way as a toy might be a prop that "plays the part" of a car in a child's game, or the toy-car's actually sliding into a cereal box makes it fictional that a real car crashes into a wall.

Sports appear to throw up an analogous puzzle. But whereas the Paradox of Fiction concerns the possibility of emoting at all about entities believed not to exist, the Puzzle of Sport concerns emoting to an extent

or intentionally-fictional entities are the intentional objects of our emotions. (1) is false on the causal reading. Beliefs can be false and an emotion's cause need not be its object; boredom might cause one to desire food. Moreover, Walton's (principal) claim is that fictional entities are not the intentional objects of the responses, and not that the responses are not emotions (though the claims are related). See (Walton 1990, p. 196-197), (Walton 2015c), and (Stear forthcoming).

9 See (Matravers 2014), especially chapter 8.

10 I provide here the barest details of Walton's expansive theory. Readers unfamiliar with it might consult (Walton 2015b, 90-92) for a useful summary. 
beyond that warranted by how much the competitive game outcome is believed to matter:

(1) The amount to which we care about something cannot (rationally) exceed the amount we believe it matters (under the same description).

(2) We care a great deal about some competitive game outcomes.

(3) We do not believe those competitive game outcomes matter very much, if at all.

More fastidiously, for any event $e$, and any (relevantly rational) agent $s$ :

(1) If $s$ has caring-attitudes of degree $n$ toward $e$, then $s$ believes $e$ matters to (at least) degree $n$.

And for some agent $s$, some competitive game outcome 0 , and some values $j$, $k$ such that $j$ is strictly less than $k$ :

(2) $s$ believes $o$ matters to degree $j$.

(3) $s$ has caring-attitudes of degree $k$ toward $o$.

Since (2) and (3) rely on relative values, rejecting either might appear equivalent. But there is an aspectual difference: denying (2) revises $s$ 's belief about how much $o$ matters up to the level of $s$ 's caring-attitude, rejecting $s$ 's "cold light of day" judgement. Denying (3), meanwhile, revises the level of $s$ 's caring-attitude down to the level of s's belief about how much $o$ matters, rejecting the appearance of intense caring in $s$ 's participatory behaviour.

$\mathrm{SMB}$, then, amounts to this. When caring-attitudes appear to outstrip a belief in a competitive game outcome's importance, this appearance is explained by make-believe (at least, where the participant is not simply irrational). As with the Paradox of Fiction, Walton denies (3). Fictionally, the participant cares about $o$ to greater degree $k$ (because fictionally she believes the outcome to matter to that degree), though actually she cares about the outcome only to degree $j$, since actually she believes $o$ only to matter that degree. The imagination bridges the gap from the belief to the caringattitude, from $j$ to $k$.

\section{III}

In this section I advance objections to $\mathrm{SMB}$ that, cumulatively, cast doubt on its plausibility. In $\iint 3.1-3.2, \mathrm{I}$ argue that two reasons for adopting SMB overgeneralize, committing one who accepts SMB on these grounds to one of two options:

A. Apply the same make-believe analysis to these other activities.

B. Do not apply the same make-believe analysis.

Choosing B presents two more options: 
B1. Identify a salient difference between these other activities and competitive games.

B2. Do not identify such a difference.

Neither A nor B1 is attractive, I argue, leaving B2. By modus tollens this gives one grounds to reject SMB. In $\int \$ 3.4-3.6$, I consider further problems afflicting SMB.

\subsection{Incongruous Caring}

Kaspar and Sumyi place a cup of water atop a door. They hear Beverly approach, oblivious. The tension rises - will she notice the cup, spoiling the prank? Will the cup miss? Beverly takes the door handle but releases it again remembering something she left behind. Kaspar and Sumyi squeal involuntarily with frustration. The wait is agonizing. Finally, just as the plan seems lost, Beverly enters. She is drenched. The pranksters cry with laughter.

Appealing to make-believe to explain apparently disproportionate caring-attitudes towards competitive game outcomes is tempting; they are games after all. But such apparent disproportionality is common in other cases that less plausibly involve make-believe. Consider the practical joke just described; narrowly catching or missing a bus; losing a desirable parking spot; finishing War and Peace; having the radio cut out, or threaten to, halfway through a gripping story one happened upon; making a green (or yellow) traffic light; settling a petty argument; binge-watching a TV series; having the last word; looking up trivia once made curious; solving a puzzle; completing a flawless musical passage.

Take puzzle solving. The moment of epiphany can be intense. Yet, while reasoning skills are valuable, the problem-solver might acknowledge that her understanding any particular solution does not really matter. She could drop the puzzle and move on unperturbed. Yet, as she finally grasps a solution, she might delightedly throw paper and pencil into the air, especially if the problem is difficult. The solution could be to a sophisticated derivation, or a Sudoku puzzle, yet elicit the same reaction. Some such activities will seem sufficiently game-like to motivate SMB, but not all. Think of the agonized lunges and yelps we perform when spotting a teacup slip off a tray, or a puppy adopting that familiar squat over the carpet. Such cases involve the kinds of apparently "life and death" reactions any relevant sport fan exhibits.

Nor need these moments be sudden and intense. I recall in 2010, while in line for Barack Obama's Commencement Day speech at Michigan's Big House, a throng gripped by the zip on someone's fleece. As she and her partner took futile turns to fix it, a small crowd formed to watch, swapping notes on zip-fixing, predicting the outcome of each attempt. I never saw her repair it. But had she done so, one could imagine a cheer going up, or applause, and not necessarily ironically. Generally, such events are not believed to warrant total focus, cheering, or agonizing, yet often cause us to focus, cheer, or agonize. 
Few, perhaps none, of these examples involve make-believe; their proximity to (or identity with) ordinary unproblematic cases of caring mean that explaining them through make-believe applies the notion too generously; one begins to lose one's grip on how caring about something differs from fictionally caring about it. In a slogan: if make-believe is everywhere, then it is nowhere. They require a different explanation, which can be conservatively extended to sports.

\subsection{Quick Recoveries}

Another motivation for SMB is the apparent incongruity between our caring attitudes towards competitive game outcomes and our quick recoveries following disappointing ones. This resembles our quick recoveries following fictional tragedies. However, such recoveries are not limited to make-believe games. Similarly, we can often move past extremely significant events very quickly. Take the evening news. We frequently see lives destroyed by war, repression, and (un)natural disasters. This may move us deeply. Yet, often, we put down our smart-phones, turn off our televisions or radios, and find our concern quickly lost in the dust of mundane activity.

SMB's defenders have a rebuttal. Bad news may not continue to affect us because we can put it out of mind. But often, if we remain vividly aware of the news, or are reminded of it, it continues to affect us. Sports "disasters", however, are different; vivid awareness and reminders will likely fail to affect us. Moreover, whereas news tragedies that induce our concern often involve distant and unfamiliar people, only sporting cases close to home ever move us to express a similar degree of apparent concern. (Walton 2015a, 77n).

Responding to these points in reverse: first, even conceding that concern for competitive game outcomes is typically egocentric, there are exceptions. During the 2012 Olympics, double leg amputee Oscar Pistorius delighted many by finishing second in a $400 \mathrm{~m}$ qualifying heat alongside able-bodied athletes. And many were devastated when he finished last in the semi-final. The reasons for this interest were probably multiple with both symbolic and instrumental dimensions. But I suspect this interest did not entirely redound to Pistorius' role as symbol or catalyst for disabled achievement. Nor was it plausibly explained by fans' existing investment in Pistorius; many had not heard of him before the Games. The interest seems also to have concerned his simply doing well for its own sake. Similarly, millions felt tremendous pity when Brazil were "humiliated, humbled, and taken apart" (BBC 2014) in the 2014 World Cup semi-final. Germany thrashed the hosts 7:1.

Regarding the first objection SMB's proponents could raise, it is unclear that a tragic news story will continue to affect one any more than a comparable sporting tragedy. Certainly, if a team one loosely follows loses a regular match, this is easily put out of mind. But similarly, if a vaguely familiar country suffers a small misfortune, this will not continue to affect one much either, even if it ought to. Moreover, while it is true that bad news close to home will often continue to move one, this is clearly true of 
some competitive game outcomes, too. I have a friend around whom, a year after the event, I dared not speak of the Vancouver Canucks' defeat to the Boston Bruins in the Stanley Cup final. The extent to which he considers that defeat "philosophically" is only the extent to which one might consider any setback with which one has "made peace" in such terms. Moreover, the tendency to move past sporting tragedies may have more to do with social norms than our beliefs about how much those events matter. Of course, this kind of case is not decisive because SMB employs an existential rather than a universal quantifier; the claim is that some sports participation involves make-believe, not necessarily all. But it reminds one that our relationships to sporting events are not always as easily distinguished from our relationships to other events as suggested.

It is important when comparing cases that they are relevantly similar. There are innumerably many factors determining the affective profile of any event - the extent to, and manner in, which something strikes us as important, motivates us, excites our interest, and so forth. These factors influence the depth and longevity of our emotional responses to an event, often in ways impervious to introspection. These include, but are not limited to, our spatiotemporal proximity to the event, our ties to those involved, how engaged we and our wider communities are with the circumstances to which the events relate, etc. The observation that we recover quickly from sporting tragedies is only evidence for SMB if the following holds: (a) we recover slowly following non-make-believe tragedies and (b) these tragedies have similar affective profiles to the sporting tragedies under consideration. Pointing out that we recover quickly following defeat in an impromptu game of Noughts-and-Crosses, but slowly from hearing that our sibling's house was razed, for instance, is unhelpful; the two events have drastically different affective profiles. One must also take care making these comparisons, since determining the comparability of two events' affective profiles relies on judgements about whether make-believe plausibly plays a role in attitudes about those events. A quick recovery from an event is precisely the kind of datum that helps one determine whether SMB-style analyses apply to the event, and how significant it is. One can take a quick recovery to show that event A matters less to the agent than event $\mathrm{B}$, from which recovery is slow, and that thus $\mathrm{A}$ and $\mathrm{B}$ are not comparable. Alternatively, one can take the quick recovery to show that the agent engaged in make-believe, thus restoring the comparability of the two events' affective profiles. Using such comparisons to adjudicate SMB's plausibility, therefore, runs the risk of vicious circularity.

A different objection is that the class of activities falling under the make-believe analysis are hardly clear. Thus, it begs the question to claim that watching the news, say, does not involve make-believe, and to use these activities to discredit SMB. ${ }^{11}$ I think one can plausibly assume that certain activities (like watching the news) do not involve make-believe in any way relevant to the discussion. Presumably some activities must not involve

11 Thanks to Derek Matravers for this objection. 
make-believe in the relevant way, otherwise SMB would be almost vacuously true, and its proponents' focus on competitive games arbitrary. Competitive games were supposed to present a particular puzzle; but if the kind of make-believe in question is everywhere, they no longer would. ${ }^{12}$

SMB proponents might instead point to the similarity in how we reassure participants in both make-believe and competitive games: "it's only a game" (Walton 2015a, 75). However, on reflection, such consolations are not restricted to competitive and make-believe domains. "It's only money", "Don't cry over a boy!", etc. all function in the same way, as do judgements about how appropriate attitudes and emotions are: "Don't be scared, it's just a spider", "Don't be angry, it's just a small setback", etc. SMB's proponents might insist that reassuring the sports participant functions to shake her out of her pretence, returning her to reality, whereas in my examples, the consolation reminds the sufferer of the "bigger picture"that the object of her concern is less significant than she thinks. In other words, the consolation reminds the sport spectator, as the story-listener, to move from one world back to another, whereas elsewhere, it merely corrects an incorrect belief, or value-judgement. ${ }^{13}$ Whether one finds this persuasive, however, depends on how antecedently plausible one finds SMB. But, as this is the very view in contention, leaning on whatever plausibility it has begs the question.

If abandoning SMB seems unattractive, the alternatives are $\mathrm{A}$ and $\mathrm{B} 1$, given above. On A, one bites the bullet, extending SMB to my examples. On B1, one identifies a relevant difference between my examples and competitive game cases. I know of no such difference, although nothing I have said rules it out. At minimum, I have shifted the burden onto SMB advocates to identify one.

\subsection{Representational Competitive Games}

A different consideration that might lend plausibility to SMB is that many competitive games-chess, whack-a-mole, video games-are mimetic in ways that involve make-believe. Moreover, many sports appear to involve simulations of, and thus make-believe about, ancestral practices. Fencing, for example, originates in recreational sword-fighting, which originates in preparing for lethal combat (Garrett et al. 1994, 1-3). Wrestling, archery, and shooting probably share similar histories. Plausibly, many of these activities began as simulations incorporating make-believe for the development of "real-world" skill-sets. Proto-fencers might have imagined engaging in real duels, proto-wrestlers in real fights, etc.

However, despite all this, these activities' representational elements are orthogonal to their being competitive games. Gradually, perhaps instantly, proto-athletes would have learned that a simulation's value was not merely

12 Thanks to Sarah Buss for helping me see the force of this reply.

13 Another possibility is that the consolation might itself be part of the game. If so, the consoling friend would fictionally be correcting a false belief, or value-judgement. 
parasitic on the simulated activity; they would have come to value and enjoy simulation for its own sake. Thought would have been devoted to refining the competition itself, as modern sports go on being refined, with the introduction of rules and conventions to define courses of action available to competitors. It is this moment at which the original make-believe element, the simulation of real-world activity, becomes ancillary to the competitive activity. The competitors' sense of which actions are appropriate is no longer guided by the make-believe game's principles of generation (that they are "fighting to the death", say), but by stipulative rules determining not only how to win the game, but also the permitted means to victory. Consider two children playing make-believe swordfighting with small planks. In the heat of "battle" one may grab the other's "sword" and throw it aside or use the "blade" to "scoop dirt" into the other's eyes. Such actions count as playing the game because they cohere with the operative principle of generation - that the planks are swords and the children sword-fighters. Likewise, proto-athletes simulating a real fight might have allowed themselves such improvisational flourishes as swordgrabbing and dirt-scooping (perhaps even in the absence of dirt), supposing the simulation's object to be to "defeat" the opponent by any means necessary. Fencers, by contrast, enjoy no such liberties. They are playing a sport whose object is to meet a stipulated success condition without flouting any of the stipulated rules. That their instruments resemble swords or that they engage in "lunges" and "attacks" is of anthropological or sports-historical interest, but it says little about the competitive game as such.

Another game may help drive this point home. Chess is the quintessential competitive game suffused with make-believe. A chessboard is effectively a pretend battle field for two advancing armies. The pieces represent political and military figures, their strengths matching their rank (the King is an exception, though perhaps one is to imagine he is past his prime). But this make-believe layer is superfluous to chess as competition; one could substitute non-representational pieces to play an otherwise identical game. If anything, chess, fencing, and other representational competitive games establish what Walton calls a "prop-oriented game", in which our interest in the fictional content derives from our interest in understanding the props themselves (Walton 1993). Still, this has no bearing on whether such games involve make-believe in the respect intended by SMB_qua competitive games. ${ }^{14}$

\subsection{A Further Puzzle}

Competitive games and traditional fictions typically differ in their representational content. While novels, portraits, etc. afford rich fictional

14 Fencers might pretend to be sword-fighters to perform better, as method-actors pretend "from the inside" to be their characters. But this is neither necessary nor central to fencing or sport generally. Nor, as I show below, can this kind of makebelieve confirm SMB. 
"worlds", ordinarily sports do not. ${ }^{15}$ On Walton's account of fictionality, $p$ is fictional in a work $w$, or $w$-fictional, just in case one ought to imagine $p$ as part of playing $w$ 's make-believe game (in the relevant context, in order to fully appreciate $w$, should the question arise) (Walton 1990, 39-41, 57-61). Which propositions are sports-game- $x$-fictional? The $x$-fictional propositions, if any, are nearly the same propositions true of the contest at the actual world. This kind of coincidence is common enough: Flora Nwapa's Efuru makes it fictional that Igbo people live in Nigeria, which is true in actuality. But competitive games are not representational as works of fiction are. Players do not "stand for" fictional characters as actors do. When Serena Williams serves an ace, she really serves an ace. There is seemingly no more to it.

Appearances can deceive, however, and participation in make-believe is not always transparent. Indeed, where fictional worlds are propositionally near-identical to the actual world, it will presumably be harder to separate what one engages with literally from what one engages with in makebelieve. According to SMB, the fictional worlds participants of competitive games engage with differ only from the actual world in that their outcomes (understood broadly as throughout) are important, or more important than is actually the case (Walton 2015a, 78).

Unfortunately, this proposal raises a puzzle as perplexing as the one it purports to solve. The old puzzle is (roughly) this: how can we care about something we do not believe matters to us)-i.e. competitive game outcomes? The new puzzle: how does this kind of make-believe motivate the behaviour SMB is intended to explain? Consider ordinary fictions. In reading Superman, for instance, one might cheer Superman on and wish ill upon Lex Luther. This is intelligible because Superman is a good guy trying to save the world and Lex Luther is a vainglorious plutocrat. On SMB, however, competitive games make no propositions fictional that could rationalize our attitudes towards the game's outcome, beyond those true at the actual world. How, then, does positing such a fictional world help explain our apparently incoherent attitudes towards competitive game outcomes? As Walton notes, "there are no ready-made good guys and bad guys in sports". He continues:

[S]ports fans are free to choose for themselves; each has his or her own personal heroes and villains. [...] you are not getting anything wrong if you root for the Tigers instead of the Blue Jays, or the Blue Jays instead of the Tigers. (Walton 2015a, 80)

Since there is no fact of the matter in the fictional world to determine which teams or outcomes deserve our support, how does anyone manage to "care" about them at all-not merely so as to make it fictional that one cares, but so as to induce the manifest enthusiasm SMB purports to explain?

15 As just seen, some competitive games incorporate representational elements; on this, see (Wertz 1985, 15-16). 


\subsection{Illegitimate Make-believe}

One possible response to the foregoing is that sports participants fictionally treat certain (actually) insufficient reasons as sufficient ones for cheering one way rather than another; while the competitive game's "work world" offers no facts about who to support, the participant's "game world" does. ${ }^{16}$ Such reasons might be an attractive team jersey, or a name shared with a competitor. Where one is competing oneself, this may by itself function as a reason. But this response raises a further question. If we treat weak reasons as (fictionally) strong ones, or even non-reasons as reasons, why are we so uncreative in this endeavour? It is interesting that spectators do not ordinarily pretend, for instance, that their team must win to avert death or secure world peace. If things were as the response suggests, such interestenhancing imaginings would seem warranted. Game worlds embellished in these ways would (fictionally) give one reason to prefer certain outcomes over others.

It is worth considering a clear example of using a competitive game to engage in make-believe to see how it differs, if at all, from the kind of make-believe just considered. At times, when stuck in an airport, say, I find myself watching a football match between two teams I barely know. If one is playing in black and white (Germany's colours), I can amuse myself momentarily by pretending that Germany (a team I support) is playing, provoking a make-believe interest in the game. But sustaining this imaginative project is difficult and, in any case, never arouses the same passions that really watching Germany play affords. More importantly, the possibility of such a make-believe game cannot confirm SMB, since it is the kind one could play with any event or object; in principle, anything can serve as a prop that combined with a principle of generation generates fictional truths. ${ }^{17}$ Call this kind of non-SMB-confirming make-believe illegitimate make-believe, as opposed to the legitimate kind that would confirm SMB. Now one can ask: how do legitimate and illegitimate make-believe differ?

Walton appeals to the possibility that one can choose one's favoured teams and players for inadequate reasons-even "on whims" (Walton 2015a, 76). However, it is more plausible that one must believe one has some actual reason to make and sustain such a choice. In addition to competitive game outcomes that arrest us, there are those that do not. Sometimes this is for reasons that explain comparable failures in traditional

16 'Work world' and 'game world' are Waltonian terms of art. A work world is the set of propositions a work makes fictional. A participant's game world is the set of propositions fictional in the game she plays using the work as prop, which standardly includes the work world (Walton 1990, 58-63).

17 This is why I am unsure what evidential weight to give comments competitors make in jest. Walton identifies cases where players say to one another "You rat!" or ask "What did I do to deserve this?" etc. during friendly competition (Walton 2015a, 82-83). This kind of banter certainly involves make-believe. But because it can be superimposed onto any activity, I think this banter is merely a very general and ancillary form of make-believe, much like the military make-believe in chess. 
fictions. A film, say, might fail to make one care about what happens because it is poorly produced, has wooden acting, etc. A competitive game might similarly do so for lacking incident. Sport is different, however, in that I may exhibit intense caring-attitudes towards the outcome of a game between Germany and Spain, while failing do so with respect to the outcome of a Barcelona $v$ Real Madrid match, even if the quality of the two matches is comparable. The matches might involve an equal amount of incident, have an equal number of interpersonal rivalries, etc., and yet it might still be that one engages me while the other does not. How does one explain this? The obvious answer for most cases is that there is a salient difference-namely, that I have German friends but no Madrileño ones, or that Germany but not Barcelona is a team whose history I know. These are the kinds of facts from which fandom is built. But notice that these look like actual reasons for caring about one team and not another, comparable to reasons for preferring that one's own child win a prize over another's. If asked why one has this preference, "It's my child!" counts as good an explanatory reason as any (even if it is not universally normative). ${ }^{18}$ At least, this reply does not only fictionally report the parent's reason. The alternative, that one merely fictionally has reasons-perhaps one imagines being from Barcelona, or defeat entailing catastrophe-appears to consist in the illegitimate make-believe just dismissed. The SMB proponent must offer a way to distinguish the illegitimate from legitimate kinds of makebelieve, in the sense intended. The possibility of the former vis-à-vis sport would be very tame evidence for SMB, but if it cannot be distinguished from the latter, tame proof will be all there is.

\subsection{Authenticity}

A final consideration challenging SMB is that it is important in sport that players really try. In this respect, sport differs significantly from theatre or film, say, in which actors typically dissemble. Where players feign effort, or play toward a pre-arranged outcome, participant interest disappears or changes entirely. ${ }^{19}$ This is why sport-lovers detest match-fixing. Matchfixing damages the integrity of sport not merely by being deceitful, but by undermining sport's authenticity. I suspect this explains why "sports" whose outcomes are known to be predetermined must be integrally supplemented with other forms of entertainment to make them watchable. In Pro-Wrestling, for instance, elaborate soap-stories hold the various "fights" together. The Harlem Globetrotters must incorporate freakish feats of skill, pranks, and non-regulation props such as trampolines to generate interest in their games. This supplementation is needed in the same way that a broader narrative is needed to sustain interest in more traditional fictional sporting encounters (e.g. the Rocky films). The need for

18 ' $\mathrm{My}$ ' is here intended at the level of character not content; not everyone has an obligation to want my (i.e. Nils') children to win, adorable though they are.

19 Former US tennis star Andy Roddick captured this in a post-match interview: "There is no script in sports [...]. I think that is what makes it the best entertainment in the world." (Telegraph 2012) 
authenticity is interesting for my purposes precisely because nothing comparably authentic is (ordinarily) required to enjoy traditional fictions. If sports participation involved make-believe, one would expect authenticity to be irrelevant to one's ability to get behind a competitor.

A possible response is that what fictionally spectators care about is that their side actually wins a genuinely contested encounter. However, since this simply restates the difference between sports and traditional fictions without explaining why sports spectators require authenticity it is dialectically unhelpful. A different response is to contend that traditional fictions and make-believe games do require authenticity. Many make-believe games involve props that play important, if not essential, roles in generating fictional truths. A child that tells her playmates to "imagine the car crashes into the wall" in lieu of actually guiding the toy car into the cereal box, or a sadomasochist "top" who lethargically informs the "bottom" that she is whipping him, rather than actually doing it, probably fails at something important to the others' make-believe. Actors are sometimes criticized for "phoning in" a performance. ${ }^{20}$ Are these comparable cases of inauthenticity? They are crucially different; the analogue to these cases is not authentic competition-competitors trying to win-but rather "competitors" trying to convincingly appear as if trying to win. This demand for "authenticity" concerns successfully executing the pretence; the demand for authenticity in sport concerns whether players compete. It is one thing to criticize Sylvester Stallone for not playing Rocky "believably", another for not actually trying to knock out Dolph Lundgren.

In fairness, competitive games relying predominantly or exclusively on chance place limits on authenticity. When two people wager on which raindrop will reach the windowsill first, or which "horse" will win a race determined by dice throws, talk of authenticity is strained, if not totally senseless (letting the die fall as it may does differ from scripting how it falls). I find SMB most plausible in these cases, as opposed to full-fledged sports, probably not coincidentally.

\section{IV}

SMB faces serious difficulties, many of which result from undercutting the puzzle it addresses. That sport presents no special puzzle is a serious possibility. That said, the feeling that something about our engagement with competitive games needs explaining is hard to shake, even if this oddness extends beyond such games. Competitive games do elicit incredible excitement about events that can seem trivial (consider kids racing to the next lamppost).

My fear that accepting SMB commits one to embracing a similar analysis for many other activities does not stem from a general skepticism about whether make-believe extends beyond appreciating works of traditional fiction or playing children's games. I am thoroughly persuaded that make-believe is at the heart of a number of other practices, such as

20 Thanks to Will Thomas for this objection. 
metaphor, irony, and mental simulation, and am sympathetic to forms of anti-realism about various domains couched in terms of make-believe. Nor am I persuaded by the sillier criticisms directed at the theory in generalthat participants in make-believe (sometimes) do not think of themselves as engaged in make-believe, or that they "really feel" emotions. ${ }^{21}$ My chief worry, to recall $\int \$ 3.1-3.2$, is that SMB threatens to overgeneralize to other activities in which we appear to care perfectly literally about something, but where our caring-attitudes still seem overcooked. Given the additional worries raised in \$\$3.4-3.6, a new argument is needed if one wishes to extend SMB beyond sport instead of withholding it altogether.

What is the alternative? Below, I offer a new account that embraces the idea that our attitudes to competitive game outcomes lie on a continuum with those directed at "ordinary" outcomes. I argue that the apparent oddness our attitudes towards these outcomes exhibit can be explained in terms of a general volatility of our caring-attitudes. I end by considering how make-believe might still play a role in my alternative account.

Our motivational attitudes, including what I have called our "caringattitudes", are more volatile than the Puzzle of Sport suggests. When someone is caught up in some activity, including competitive games, the things she immediately cares about can shift dramatically. Different contexts can cause certain motivational attitudes to become salient, or grant us completely new concerns. Competitive games, if we let them, can supply such contexts. One way to account for the discrepancy between our sober proclamations about a competitive game outcome's importance and the extent to which those outcomes move us as participants, then, is to appeal to the volatility and context-sensitivity of our motivational attitudes.

Attitudinal volatility is familiar on reflection. In addition to the examples from $\int \$ 3.1-3.2$, adherence to popular fads, concern for others present and others absent, and passing flirtations with new hobbies all seem to exhibit the phenomenon. Sexual desire is like this for many people. One has to get "in the mood" and once one is, it can be as though little or nothing else matters. If the moment passes without gratification, so eventually will the mood and with it the intense orientation of one's motivational attitudes. But the phenomenon extends beyond the bedroom. Some cases exemplify straight irrationality (sexual desire might be such a case), but not all. A political activist who works for months agitating against the passage of some bill might leave the activist world because of new responsibilities. When, later, she does not know whether the bill ever became law, this does not show that her concern was insincere or the product of irrationality - unless one's theories of sincerity or rationality are implausibly demanding - nor that she re-evaluated the merits of the activist cause. Participating in sport exhibits a similar attitudinal volatility. For a brief moment, or several seasons, a sports participant comes to care about a relatively narrowly-focussed set of outcomes, unencumbered by questions about whether these outcomes are ultimately justified by the ends to which they are connected. Later, perhaps, she ceases to care, or care as much.

21 See, for instance, (Carroll 1990, 74). 
One intriguing possibility is that our ability and tendency to focus our concern in this way might be built into the very architecture of human action and affect. Indeed, one can mobilize a kind of transcendental argument, in addition to an obvious evolutionary one, for its necessity to caring. If many people have no idea of a final substantive end or ends (to adopt an Aristotelian picture of practical normativity), and yet also care about and take the means towards goals, then it cannot be a requirement of an agent's performing an action, or caring about something, that she do these under the description of serving some substantive final end, explicit or implicit (I say 'substantive', because agency may require a belief that one acts toward an un(der)specified 'good'). ${ }^{22}$ This suggests that the teleological story we bear in mind when we act or feel concern is often truncated; the substantive ends we consider, insofar as we can divine them at all, are only a few links in the justificatory chain removed from the action being undertaken. ${ }^{23}$ Caring about competitive game outcomes often exemplifies this truncation at its lowest limits; the competitive game outcomes are only one or two degrees removed from the ends we take them to serve, or else are their own end. This explains why caring about competitive game outcomes can seem more puzzling, more absurd, than caring in "ordinary" cases; when I care about meeting my boss' deadline, the chain of means and justificatory ends is more protracted. Why should I care about meeting the deadline? To process the shipment punctually. Why care about that? To guarantee the delivery. Why care about that? To satisfy the customer, and so on. This chain (more likely a web) of justifications will peter out somewhere, who knows where? In the sporting case, conversely, the chain peters out obviously and (almost) immediately. This makes caring about the outcome appear more obviously arbitrary.

Why should an abrupt chain of justificatory reasons seem more absurd than a long one? In his now famous article on absurdity, Thomas Nagel describes the "backward step" we perform when we reflect on a particular situation's significance (Nagel 1971). A situation will seem absurd when pretension and reality clash, as, to use Nagel's example, when someone's trousers fall down as he is knighted. When we reflect on our individual endeavours, we often take this backward step to a vantage point from which we examine and assess the point of the endeavour as a whole. Typically, this step reveals a standard for assessing the endeavour. Assessing one's job, for instance, one might step back and evaluate it by the standards of one's institution. One can also question the institution's value, perhaps against the standard of serving one's community, thereby also evaluating one's job from "further back". This represents a kind of zooming out process on a chain of justificatory reasons, each backward step allowing one to see

22 That we undertake projects without seeing the substantive final ends they serve may also explain their susceptibility to being impulsively abandoned or rekindled, hence, may explain attitudinal volatility.

23 My claim is not that we never have a substantive conception of our (final) ends, nor that we cannot deliberate about them. It is merely that we sometimes act without substantive final ends in mind. For an argument that we can deliberate about final ends, see (Richardson 1997). 
increasingly ultimate standards. Nearing its limit, this process reveals the grandest standards there are: "service to society, the state, the revolution, the progress of history, the advance of science, or religion and the glory of God" (Nagel 1971, p 720). Where one remains invested in a situation or endeavour despite seeing how it falls short of a standard, one is faced with absurdity or, to put it in the terms of our puzzle, incongruity. This capacity to step back and look at one's projects "with that detached amazement which comes from watching an ant struggle up a heap of sand" (Nagel $2013,720)$, is the capacity to reveal how one's motivational attitudes outstrip the importance of their objects.

Our investment in competitive game outcomes is susceptible to a similar "backward step" to standards of seriousness from which it falls short. This begins to explain the appearance of incongruity between the extents to which we care about these activities and to which we believe them to matter. My proposal is that this explanation is completed by the observation that only one or two such backward steps is typically required to bring our caring attitudes towards competitive game outcomes into doubt, because of their relative independence from many of our other commitments. Thus, it is easier to see our caring attitudes toward competitive game outcomes fall short of a more ultimate standard (as being incongruous with our beliefs from this vantage point about how much those outcomes matter-as being absurd) in the same way that, however, our caring attitudes about any activity might ultimately appear to fall short. This proposal yields an interesting, and I think correct, prediction. Ceteris paribus, caring about competitive game outcomes embedded into larger structures of competitive game (and other) outcomes to which they relate as means to ends will strike us as less absurd than doing so towards competitive game outcomes that stand alone. The idea is that, for instance, caring about scoring points in order to win a game, in order to win a league, in order to qualify for a playoff, etc. will seem less obviously absurd than caring comparably about scoring a single point to no further end.

\section{V}

My proposal is not that our motivational attitudes freely appear and disappear. This is not the only way to capture the psychology behind volatile motivational attitudes. It is consistent with this volatility that the attitudes remain fixed where they are in our psychology, but become more or less behaviourally influential in different contexts. This is how I intend the proposal. David Velleman describes the possibility that this volatility be explained by a form of meta-desire for one's actions to "make sense", the desire being to accommodate one's behaviour in a running narrative of the self. On this picture, the attitudes that explain one's caring do not disappear so much as take a back seat while other attitudes are "reinforced by the agent's conception of what he is doing" (Velleman 2002, 97-98). This selfconception is a narrative that makes sense of one's actions. The further desire to make sense of what one is doing, when combined with this narrative self-conception, promotes various motivational attitudes that fit 
the narrative to a guiding centre, and moves others to a restraining periphery. But this meta-desire does not thereby create or destroy these attitudes in the agent's psyche; it just plays them up or down. Velleman gives the example of a person pressing a point in an argument. Insofar as the agent gets "carried away", she conceives of herself exclusively as someone pressing a point (rather than as a polite human being, or conscientious colleague), and the attitudes that might otherwise motivate her to acknowledge her interlocutor's annoyance are muted (but do not disappear). She has only two hopes in such a case, according to Velleman. The muted motives might act as "unreflective restraint" on action "from the outside" as when one's desire to avoid colliding with things constrains how one runs down a crowded street. Alternatively, her other motivational attitudes — such as her desire to maintain good relations with colleaguesmight "obtrude" themselves on her attention in such a way that she revises her self-conception by coming to see that she "has more than one end at stake" (Velleman 2002, 98).

Velleman's account then suggests an attractive, if highly metaphorical, way of explaining our interest in competitive game outcomes that does not necessarily appeal to make-believe. ${ }^{24}$ We adopt a self-conception of playing the game-supporting the team, being a winner, etc.- - however consciously or not. This self-conception and our desire to make sense of our behaviour combine to put those attitudes that most chime with this self-conception (e.g. desires to cheer or try hard, or the disposition to feel the sting of defeat) in the driving seat. Those attitudes that do not (e.g. desires to be fair, be a good parent, or whatever) are consigned to a restraining role- - the role of road signs and markings on the agential highway. This can work via the same means by which an agent adopts the self-conception of one who is pressing a point in argument, thereby emphasizing and de-emphasizing attitudes in her psychology. I think this is at least roughly what happens when we "get into" a competitive game. It also offers a psychological metaphor to complement that of Nagel's backward step. Taking a backward step reveals broader standards by which to evaluate a goal, action, or practice; adopting a broader self-conception allows a broader set of attitudes to play a driving, rather than merely restraining role in action.

"Getting into" a match sometimes requires a willingness to boot-strap ${ }^{25}$ oneself into receptivity that parallels what one must often do to genuinely "play along" in make-believe games or "engage" with fiction. One might think this favours SMB; imagining typically involves constructing attitudes, including desires and interests, from nothing. But my proposal handles this fact as easily if not better than SMB and is not beset with its problems. An illustration: in 2007, my brother and I, lifelong German national football team supporters, attended a match against old rivals, England at England's brand new Wembley Stadium. For two Germans who grew up in England

24 One can adopt self-conceptions in imagination. Indeed, much of Velleman's discussion concerns such cases, which I address shortly.

25 German enjoys 'sich hineinsteigern'-roughly an active equivalent to 'get swept up in', like to 'work oneself up' but without the hysterical connotations. 
in the 90's, when Second World War xenophobia spiked with resentment (Germany had knocked England out of the World Cup in 1970 and 1990, and the European Championship in 1972 and 1996) still trickled through the generations, the fixture is always special. For similar reasons, the game is special for England fans too, and so the only seats available were far from the pitch with the die-hard England supporters. Having been subjected to abuse and even violence from English people before because of our nationality, my brother and I spent the entire game on our guard, lest we betray our loyalties. When England scored the early opener, we suppressed our disappointment and stood, applauding politely while the fans around us erupted and even ruffled our hair, confused by our equanimity. When Germany eventually equalized and (predictably) later scored the winner, we remained seated so as not to betray our pleasure. What was remarkable about the game was how numb it left us in the end. Our intense focus on self-preservation, and lack of space to allow ourselves to get into the game, drained it of its significance for us. In Vellemanian terms, our selfconception was so overwhelmingly one of being covert trespassers in dangerous territory, that any attitudes regarding the match's outcome were relegated to the periphery. This phenomenon is quite general-getting "in the mood" romantically often exhibits it, for instance-a fact, for the reasons given in $\iint 3.1-3.2$, my account can better explain.

SMB is not finished, however; the Vellemanian story is partly compatible with SMB. Among the ways to adopt a self-conception is to use one's imagination. Velleman gives the example of a smoker who consistently imagines himself to be a non-smoker, thereby adopting a selfconception as such, in order to quit. The self-conception is false at first, but brings the agent's non-smoker motivational attitudes to the fore: not smoking becomes a matter of "going on as normal" rather than interrupting a satisfying habit, and withdrawal pangs become irritations to ignore rather than urges to smoke (Velleman 2002, 99-102). Eventually, with luck, the smoker becomes a non-smoker, rendering the once merely imagined self-conception true. Blaise Pascal seems to think this a general method for acquiring religious devotion. He describes Christians as acquiring their faith "by making believe that they believed, taking the holy water, having masses said, etc." (my emphasis) while imploring the reader to do likewise. ${ }^{26}$ What goes for smoking and religion goes for sport; in a separate paper, Walton relates how David Lewis claimed to have imagined caring about a cricket team in order to eventually cultivate a genuine interest in it (Walton 1994, 72, 72n).

Adopting a conception of oneself in imagination that foregrounds motivational attitudes towards competitive game outcomes may thus explain some of our participatory behaviour. But it cannot be a full explanation for reasons given in $\$ 3$. It is only to the extent that participants like David Lewis no longer have to imagine supporting their team, I propose, that they really do so (the imagining being of the illegitimate kind described in \$3.5). Still, the foregoing discussion reveals that this limited

26 For an interesting discussion of this kind of process, see (Rosati 2006). 
role for the imagination is immune to the objections given in $\iint 3.1-3.2$. For, while it might be far-fetched to claim that our interest in "ordinary" activities involves make-believe, it is not far-fetched to claim that some of our interest in them might originate in this kind of imaginative exercise, as the smoker's case shows.

\section{VI}

I began by teasing out the claim (SMB) that participating in sport, whether as player or spectator, involves make-believe. I showed how SMB relates to a loosely analogous solution to the so-called Paradox of Fiction, before identifying difficulties for the view. The first two suggest that arguments for SMB overgeneralize. First, our apparently odd attitudes to competitive game outcomes are continuous with those toward more ordinary events that do not plausibly involve make-believe. Second, our ability to recover from tragic competitive game outcomes is not markedly different from our ability to recover from ordinary tragedies. Third, a prima facie plausible defence of SMB appealing to representational content in many games is unpersuasive. Fourth, the "facts" at the fictional worlds competitive game would instantiate on SMB would not explain participants' caring attitudes or else would involve what I call "illegitimate" make-believe. Lastly, competitive games require an authenticity from their players that other make-believe games do not.

I finished by offering an alternative to SMB. This appeals to our motivational attitudes' general capacity for volatility to explain why we can become invested in events that appear trivial from certain perspectives. This explanation appeals to a meta-desire David Velleman hypothesizes to make sense of our behaviour that, once combined with certain variable selfconceptions, amplifies and mutes different motivational attitudes in our psychology. I compared this phenomenon to Thomas Nagel's notion of the backward step to show how activities that animate us can appear trivial from different perspectives, just as they can when self-conceptions foreground different attitudes. At the end, I considered whether this

account might still leave space for make-believe and concluded that it might, although in a much more modest role than SMB claims for it. 


\section{Bibliography}

BBC 1. (2014, July 8). Match of the Day Live: Brazil v Germany, 2014 FIFA World Cup. London: BBC.

Carroll, N. (1990). The Philosophy of Horror or Paradoxes of the Heart. Routledge: New York.

Kretchmar, R. S. (2007). The Normative Heights and Depths of Play. Journal of the Philosophy of Sport, 1-12.

Kuper, S., \& Szymanski, S. (2009). Soccernomics. New York: Nation Books.

Morgan, W. J. (2007). Caring, Final Ends and Sports. Sport, Ethics and Philosophy, 7-21.

Nagel, T. (1971). The Absurd. The Journal of Philosophy, 716-727.

Novak, M. (1976). The Joy of Sports. New York: Basic Books.

Pascal, B. (2014, September 21). The Thoughts of Blaise Pascal. (A. Molinier, Ed.) (C. K. Paul, trans.) Retrieved from Project Gutenerg: https://www.gutenberg.org/files/46921/46921-h/46921-h.htm

Radford, C. (1975). How can We be Moved by the Fate of Anna Karenina?. Proceedings of the Aristotelian Society, Supplementary Volumes, 67-80.

Richardson, H. S. (1997). Practical Reasoning about Final Ends. Cambridge: Cambridge University Press.

Rosati, C. S. (2006). Personal Good. In T. Horgan, \& M. Timmons (Eds.), Metaethics After Moore (pp. 107-131). New York: Oxford University Press.

Schneider, A. J. (2001). Fruits, Apples, and Category Mistakes: On Sport, Games, and Play. Journal of the Philosophy of Sport, 151-159.

Stear, N.-H. (2009). Sadomasochism as Make-Believe. Hypatia, 21-38.

Stear, N.-H. (forthcoming). Review of Kendall Walton's 'In Other Shoes'. British Journal of Aesthetics.

Suits, B. (1978). The Grasshopper: Games, Life and Utopia. Toronto: University of Toronto Press.

Taylor, P. A. (manuscript). "It's Only a Game".

The Telegraph (2012, 3 26). Andy Roddick Revels in Fantastic Win over Nemesis Roger Federer to Reach Fourth Round in Miami. Retrieved 3 27, 2015, from Telegraph.co.uk:

http://www.telegraph.co.uk/sport/tennis/atptour/9168780/Andy-

Roddick-revels-in-fantastic-win-over-nemesis-Roger-Federer-to-reachfourth-round-in-Miami.html

Velleman, J. D. (2002). Motivation by Ideal. Philosophical Explorations, 89-103. 
Walton, K. L. (1990). Mimesis as Make-Believe. Cambridge, MA: Harvard University Press.

Walton, K. L. (1993). Metaphor and Prop-oriented Make-believe. European Journal of Philosophy, 39-57.

Walton, K. L. (1994). Morals in Fiction and Fictional Morality. Proceedings of the Aristotelian Society, 27-50.

Walton, K. L. (2015a). “It's Only a Game!”: Sports as Fiction. In K. L. Walton, In Other Shoes: Music, Metaphor, Empathy, Existence (pp. 75-83). New York: Oxford university Press.

Walton, K. L. (2015b). Existence as Metaphor?. In K. L. Walton, In Other Shoes: Music, Metaphor, Empathy, Existence (pp. 89-116). Oxford: Oxford University Press.

Walton, Kendall L. (2015c). Spelunking, Simulation, and Slime: On Being Moved by Fiction. In K. L. Walton, In Other Shoes (pp. 273-287). New York: Oxford University Press.

Wertz, S. K. (1985). Representation and Expression in Sport and Art. Journal of the Philosophy of Sport, 8-22. 